\title{
Approaching Synforms (Similar Lexical Forms) in an EAP Context
}

\author{
Sukru Nural \\ School of Education, University of Leicester, UK
}

\begin{abstract}
The paper is concerned with the phenomenon of synforms which is defined as form similarity between words, pairs, or groups of words in terms of sound, script or morphology (Laufer, 2005). Synformy has been researched within the context of language acquisition and lexical errors. However, it has not been investigated in the context of naturalistic classroom environment. The data presented in this paper were collected in an EAP teacher's classroom. Results suggest that it is important for language teachers to raise their awareness of synforms because their unpredictable nature may negatively affect the way in which teachers treat lexical items. The factors shaping the teacher's instructional decisions about synforms predominantly relate to students and lexical items. The implications and challenges of treating synforms during classroom instruction are also discussed.
\end{abstract}

Index Terms - vocabulary, synform, lexical difficulty, teacher cognition, lexis-related episodes

\section{INTRODUCTION}

Lexis has been examined from different perspectives such as language awareness, form-focused instruction and classroom interaction (Andrews and McNeill, 2005; Basturkmen et.al. 2004; Dobinson, 2001). Specific curricular areas such as grammar, reading and writing have already been examined from the teachers' perspective. Particularly spelling and reading comprehension instruction, both of which constitute the major parts of literacy, has been extensively studied with a focus on L2 (English, French, Spanish) language teachers' beliefs and practices in various educational settings in the USA ranging from primary to high schools (Sturtevant and Linek, 2003; Collie Graden, 1996; Moje, 1996; Richardson, et.al. 1991). Lexis emerged as the most oft-cited language form in the form-focused instruction literature (Basturkmen, et. al. 2004; Ellis, et.al. 2001) where word meaning, spelling and pronunciation are investigated in their own right, that is independently from one another. Yet lexis teaching as a whole has not yet been adequately researched from the viewpoint of teacher cognition (Borg, 2009a; 2009b; 2003). As Borg (2009a:4) writes, 'very little is known about teachers' beliefs and knowledge in relation to the teaching of L2 vocabulary, listening and speaking which merit research attention'. Particularly it is the teacher-related factors about lexis instruction within naturally-occurring classroom environments that remain to be investigated.

The present paper highlights a particular problem called synformy concerning the teaching of lexis from an EAP teacher's perspective - her attitude towards students' confusion due to words with a similar form during classroom interaction. Synformy is the phenomenon of form similarity between words, word pairs of groups of words in terms of sound, script or morphology (Laufer, 2005). This definition highlights that synformy is related to similarity in phonological (i.e. similar-sounding) and orthographical (i.e. similar-looking) forms. They should not be viewed as independent of each other because some synforms that come up during classroom instruction are already in coursebooks (i.e. orthographical) and some are in teachers' or students' talk (i.e. phonological). Therefore both phonological and orthographical similarity might equally be a source of confusion for university-level students in EFL settings like Turkey. English seems to embody a more inconsistent relationship between orthography (script or grapheme) and phonology (sound or phoneme) when compared to other languages such as Turkish and Spanish. Despite extensive research into word recognition with a reference to synformy in experimental settings, little is known about its role in the formal classroom instruction. Research into synforms has not been transferred to language teaching procedures or strategies and as a result teachers have not yet been provided with principled guidance as to handling synforms that become part of classroom interaction.

Schmitt (2008) pointed out that 'the form element is not given adequate importance despite the fact that there is a large body of research showing that L2 learners find the word form more problematic" (p. 335). Form may require an explicit or direct focus and thus teachers need to go beyond semantic aspects of lexis. The personal theories of teaching they hold might contribute to a better understanding of the phenomenon of synformy as it emerges in actual language classrooms. It should be acknowledged that the personal theories an experienced teacher investigated in the current study are by no means the 'whole story' of teaching and learning but this important part of the picture should not be neglected (Sturtevant and Linek, 2003). Rather than merely discussing whether synforms should be taught or not, this paper provides empirical data in the form of focus-on-lexis episodes which show why an EAP teacher dealt with them the way Tulip did. This classroom-based study is not confined to investigating lexical instruction in the context of a particular language skill; nor does it concentrate only on a dedicated vocabulary-only class. Lexical items identified in 
the syllabus were distributed across the skills areas in the EAP programme where the study took place. The main research question to be investigated is: How does an EAP teacher approach synforms in her classroom? Findings from this study, which is part of a larger study that examines experienced Turkish EAP teachers' beliefs and practices about lexis teaching, lay the groundwork for other similar studies on synform'.

\section{LITERATURE REVIEW}

\section{A. Dealing with Synformy as Lexis in the Language Classroom}

Laufer (1997) suggests that vocabulary acquisition is influenced by interlexical and intralexical variables. The former is related to the interaction between the new L2 lexical items and already familiar/known L1 words while the latter is concerned with L2 lexical items alone. Interlexical (i.e. cross-linguistic) factors fall under two subcategories:

A. Cognates: similarity of form of L1 (Turkish) and L2 (English) words, hayli- highly respectively.

B. False cognates: meaning relations between words in L1 and L2, otantik-authentic respectively.

These subcategories imply that cognates can be seen as a matter of continuum as they vary in degree. Although both types of cognates are characterised by similarity (i.e. similar forms), a cognate is a helpful clue as to word meaning while a false cognate is yet another source of confusion. By and large, it can be argued that difficulty is attributed to the similarity within L2 lexical items as far as intralexical factors are concerned. Laufer (1997:154) classifies the following difficulty-inducing intralexical factors:

1. Presence of foreign phonemes

2. Irregularity in pronunciation

3. Variable stress

4. Incongruency in sound-script relationship (consider e.g. the letter 'o' in love, chose, woman, women)

5. Inflexional complexity (e.g. a criterion > criteria)

6. Derivational complexity (e.g. authentic vs. inauthentic, and not *unauthentic)

7. Deceptive morphological transparency (e.g. disagree, dislike vs. discourse)

8. Similarity of lexical forms (e.g. historical/historic, affect/effect, industrial/industrious)

9. Specificity (the word can only be used in specific contexts)

10. Register restrictions,

11. Idiomaticity

12. One form with several Meanings: homographs

The phenomenon of synformy is conceptualised within the framework of word learnability. Synform is a major subcomponent of deceptive transparency which is a factor of difficulty which accounts for interlingual and intralingual clues in detecting the meaning of words. Laufer (1988) argues that similarity is often associated with the number of syllables (e.g. economic-economical), syllabic position (e.g. industrial-industrious), syntactic class (e.g. assumptionconsumption) and shared phoneme (e.g. competence-competition). Based on the premise that there is an underlying systematicity in the way people confuse words, Laufer states that there are certain patterns of synformic confusion which take place in the form of substitution (e.g. prize- price), omission (e.g. economical - economic) and addition (cute - acute) in a lexical item's vowel, consonant, prefix or suffix. Systematicity entails a certain degree of generalisation despite some exceptions. Systematicity is in agreement with the 'generalisation' perspective adopted by Hanna et.al. (1971) who recognise that English spelling has an underlying logic, and therefore, words sharing similar features need to be dealt with in language classrooms.

Regarding lexical errors caused by interlanguage interferences, Laufer (1991: 192) notes that synform errors would score more highly on the gravity scale and that the teacher is likely to seek appropriate teaching treatment to help learners overcome confusion of synforms. It is likely that such associations result in communication breakdown. The problem, then, is that synforms may give learners a false sense of confidence in their lexical knowledge unless they are brought to learners' attention. As Laufer (1991) puts it, synform errors could be disruptive because they reflect a sense of mismatch between the message the learner tries to get across and the meaning the listener/reader decodes. Laufer also draws attention to the difference between the organisation of L1 lexical items and that of L2 lexical items in the memory. Since the lexicon contains items that correspond to phonological structure in working memory, association is made between phonologically related items despite their semantic distinctions (e.g. cute - acute). Laufer's position stands in stark contrast to the L1 = L2 acquisition hypothesis which predicts that the way in which L1 and L2 are acquired is similar. The assumption that L2 learners are heavily reliant on phonological links between lexical items is backed up by second-language-classroom research into the influence of phonological memory. For example, Hummel and French (2010: 381) concluded that learners depend on phonological-loop processing in order to develop efficient word recognition and word retrieval skills in oral input-rich contexts. They describe phonological loop as a subcomponent of working memory which is responsible for the temporary maintenance of acoustic or speech-based material. However, this does not necessarily mean that all language learners respond in similar ways to this oral input provided by their teacher, material or peer during classroom instruction. It should be noted that synformy is not only related to phonological similarity but it is also to orthographic similarity which might be a source of confusion for university-level students in EFL settings, who are perhaps more likely to encounter new words in written form. In investigating the factors making a particular word difficult to learn in a bilingual class setting (Brunei), Henry and 
Metussin's (1999:19) analysis of student translation errors (English-to-Malay) suggested that association was the most common type of error followed by part of speech and synform respectively. This implies that 'association' cannot be relegated to meaning alone, but rather it can be linked to lexical form which characterises synformy. Taken together, research findings highlight that synforms are a shared source of difficulty for language learners irrespective of their L1.

Issues such as the students' understanding of lexical difficulty, the consistency between the teachers' and students' views and teachers' awareness of vocabulary difficulty has also attracted a great deal of attention from applied linguists. In their research on the Japanese high school EFL teachers' perceptions about learner difficulty in vocabulary learning, Smith and Tajino (2003) found that teachers' perceptions of learner difficulty in vocabulary learning are mostly affected by intralexical factors (\% 39.0) as opposed to cross-linguistic factors (\% 13.4). According to their report, although teachers agree on which words were the most difficult, their explanations of their decisions about lexical difficulty do vary considerably. A more recent study of McNeill (2005:111) identified the most frequently cited aspects perceived to be difficult by teachers which include derived words, polysemy and transparency (i.e. synformy). It is worth emphasising that the latter is also the case with the students involved in the study of Bensoussan and Laufer (1984).

The apparent characteristic shared by the above-mentioned studies is that most of them investigate lexical difficulty by having participants preview a reading text and underline the easy/hard words therein. Classroom-based studies could also provide further insight into the subtleties of this particular difficulty-inducing factor in lexis learning and teaching. This is not to underestimate the importance of examining the issue of synformy in the written mode (e.g. coursebook), though. Laufer classified synforms into different categories (see attachment) and validated synform errors through written tests and left the decision to the teachers' judgement whether to deal with synforms. As McNeill (2005: 122) cautions, what remains to be established is whether teachers' awareness of synformy leads to more effective teaching. This lends support to the proposal that the notion of language awareness should also include learner language awareness, in addition to teachers' knowledge of and competence in L2, as outlined by Andrews' (2001) model of TLA (teacher language awareness). However, it is beyond the scope of the paper to investigate whether the students' views are congruent with that of teachers.

Laufer (2005) cautions against teaching synforms in tandem and recommends that teachers can have students practise synforms after all members of the pair have been encountered individually. She further suggests that teaching words with formal similarities (affect-effect) and semantic similarities (buy-sell) can be counter-productive because they are likely to become cross-associated in the learner's mind. Her recommendation is grounded in cognitive load argument which suggests that 'pupils have to spend twice as much mental effort trying to remember which of the pair fills a particular lexical slot' (Nation, 1990). However, in terms of teachers' practices, focus on form is considered as a behavioural phenomenon (Basturkmen, et.al. 2004: 264). That is why the difficulty level of a word is not limited to language variables alone; rather they also depend on factors including teachers' and students' own previous language knowledge, content knowledge and interests (McNeill, 2005: 123). Awareness of students' previous learning and their abilities is a prerequisite to identifying vocabulary problems as they arise during classroom instruction. As Barcroft (2004) puts, the issue appears to be not whether but when to place the focus on word form and word meaning. There may be some occasions in which teachers give quick explanations as to the difference between two or more similar lexical items for practical reasons such as completing an immediate task, satisfying learners' curiosity and correcting errors in writing. One way of examining these dimensions is to explore teachers' views and personal theories which are considered to have a crucial role in shaping their classroom practices. The present study examines this aspect and explores how an EAP teacher dealt with the lexis instructional instances related to synforms.

\section{B. Teachers' Personal Theories}

A wide recognition of the crucial role of lexis in language learning and teaching leads various authors to come up with sets of principles offered throughout the literature (Laufer, et.al. 2005; Folse, 2004; Hunt and Beglar, 2002; Barcroft, 2002; Sokmen, 1997). However, the suggested principles cannot be readily implemented for several reasons. Firstly, anecdotal evidence suggests that they are not practically focused enough to allow EAP teachers who are often required to make instant decisions in real time. Secondly, the majority of those principles are slightly biased towards listening and reading skills; particularly, 'reading' is overrepresented while writing and speaking is underrepresented. Thirdly, some principles say what teachers should not do (hence don'ts): 'Do not teach several new synforms together (i.e. similar lexical forms like cancel/conceal); 'Do not count on guessing strategies to replace vocabulary knowledge'. While a teacher might prefer to teach confusing words that may sound similar but have different meanings during writing activity so that students use lexical items more accurately, the same teacher might avoid doing so during a prelistening activity to enable students to understand the general idea of a given listening material. It is likely that teachers do not simply adopt such expert principles, but interpret them according to their respective theories of teaching, sense of plausibility (Prabhu, 1990) and classroom contingencies alike.

Commentaries on teachers' theories underlying their particular practice are based on not only a combination of what was observed what the teacher said about the observed classroom events, what the teacher said beyond and independent of these events. The dynamics operating at the micro-level are associated with immediate antecedent and planned classroom events such as the teachers' plan for the lesson, students' queries, responses and errors. These micro-events are particularly the case with lexis teaching for which teachers need to make instant decisions on whether they need to give immediate or delayed or sometimes no instructional intervention on a particular lexical item generated by students. 
This is partly because of the interrelated and multi-layered nature of belief systems. Perhaps that is why Basturkmen et.al. (2004) do not attempt to determine whether teacher practices represent their beliefs; instead, they emphasise that what needs to be investigated the extent to which teachers' beliefs are reflected in their practices. Nevertheless, investigating such relationship necessitates a closer analysis of actual instances of practice (Breen, et.al. 2001). Those instances are operationalised as focus-on-lexis episodes (FonLE) which are to be elaborated in Data Analysis section of the paper.

\section{METHODOLOGY}

\section{A. Context}

The study took place in a university-based School of Languages in Turkey. Since existing coursebooks with notionalfunctional syllabus could not fully address the academic needs of students, teachers on the foundation programme at this School devised an explicit syllabus on the basis of the Academic Word List (Coxhead, 2000). They constitute a syllabus of approximately 3,000 words to be presented over the course of one academic year within the program.

\section{B. The Case}

The participant is an EAP teacher, as mentioned earlier, who is referred to as Tulip (a pseudonym) throughout the paper for anonymity's sake, teaches 20 intermediate level adult learners aged 18-20. Tulip has majored in English Language Teaching Education in one of the English-medium Turkish university. Tulip has 10 years of teaching experience, she has been teaching for about 4 years in the institution mentioned earlier and 6 years elsewhere. Her classes are by no means 'vocabulary lesson' in their own right, but they are based on integrated four language skills of reading, writing, speaking, and listening.

\section{Data Collection}

Data were collected from a teacher's lexis teaching practices of 10 hours of classroom observation. The two types of evidence presented throughout the paper include the naturally occurring FonLE taken from the transcripts of lessons observed and the teacher's decisions about the episodes elicited through stimulated recall interviews. As Seedhouse (1997: 343) puts it, 'close examination of classroom transcripts may reveal just how skilful teachers can be at finding practical solutions to thorny theoretical problems'. The strength of using the transcripts lies in their potential to capture the complexity of the classroom interaction in which teachers and learners are involved in different ways, yet the episodes are by no means comprehensive. The data concerning teacher's decisions were collected using stimulatedrecall interviews following each observed lesson. It is worth noting that stimulated recall interviews served to initiate a discussion of teachers' beliefs about their practices and the underlying influences rather than necessarily the recall of simultaneous thought processes (Borg, 2006: 219). Teachers were shown a clip of teachers reflecting on classroom events. This would give them an idea about what a stimulated recall session involves. The role of the researcher is to make sense of teachers' decisions and practices rather than judge or evaluate them.

\section{Data Analysis}

The interview data became the focus of analysis and observational data in the form of transcripts which highlight the teaching episode the participant commented on. Following a similar categorisation technique used in Basturkmen, et al. (2004), data analysis begins with identifying the characteristics and themes of FonLE in which lexical items are topicalised. The term 'topicalisaton', coined by Slimani (1991), denotes initiation of lexical items that are mentioned, repeated, focused upon and had speaking turns taken around them. The topicalisations are usually in the form of initiation, elicitation, explanation or feedback about lexical items. They could include single or several exchanges between the teacher and student(s). These instances of topicalisations regarding lexical items are considered within a larger unit called FonLE, which, alongside teacher comments, provide empirical grounding for the issue of synformy within formal language instruction. As long as teachers themselves comment on the items in one way or another, those items are considered as a part of 'teaching', be they lengthy or short. The attention that needs to be paid to a word before it is considered to have been taught varies in degree, that is, a teaching episode can involve single or multiple turns. There are occasions where teachers focus on the form, meaning and use of the words in not only conversational but also in didactic fashion.

It may be difficult to identify the starting point and ending point of FonLE due to the simultaneous nature of classroom interaction. Nevertheless, some expressions in classroom talk such as 'what's the synonym of this word?' and 'Is this a word you know?' can help identify the starting points. If a related but unplanned lexical item comes up while the primary focus is still on another item, this will be analysed in connection with the last lexical item taught. A situation of this kind may occur in the introduction of a theme around which a number of lexical items cluster. The endpoint occurred when the topic changed back to a focus on a different lexical item independent from the pre-targeted one. Apart from describing what lexical items they teach how and why they teach the way they do, they will be asked to confirm or disconfirm the hunches or predictions the researcher tentatively makes during observation.

\section{FINDINGS}


The current study found that the teacher whose personal theories and classroom practices under investigation, articulated her personal theories underlying not only her approach to lexis teaching as a whole but also its particular aspect, 'synforms', the major focus of the paper. The findings to be presented in this section should be read within the context of the following illustrative account:

"...[W]e don't really have enough time to prepare thoroughly enough for lessons, a lot of my teaching is mapped out roughly before class and happens in a rather spontaneous way. I think it would be great if I had the time to think about how I can explain problematic items. I often do identify these items, but don't actually think about how I'll explain them. I like to resort to eliciting as much from students as possible, but that works better with well-thought out questions, so if I am not to introduce the item myself I need to think of questions that students can answer on their way to discover the meaning.,

The above account highlights that Tulip drew her previous teaching experience as she provided an anecdotal justification for her attitude towards the treatment of similar lexical items. The teacher acknowledged the problematic nature of synforms and concomitant challenges it might pose to learners, saying that:

"Students are making the sounds, erm... phonological associations .... they are coming with the associations and the meaning is similar they say they must be similar in meaning as well. Or they have one meaning in mind and they cannot find the exact word and they go for the words that sound similar".

Her belief in the necessity of responding to students' confusion in one way or another can be understood in her expression '...we cannot ignore them [similar-sounding words]'. Tulip expressed a preference to deal with those lexical items having shared meaning (i.e. semantically related words) on occasions the students or the teacher elect to attend to form even though no error in the production of the form occurred (i.e. pre-emptively). Tulip tended to present word meanings by making use of word formation techniques using the whiteboard, an indicator of the extent to which she drew students' attention to lexical items. When it comes to synforms, however, her treatment is rather distinct from her regular teaching of non-synforms. She was observed to have focused mainly on the meanings of synforms at the expense of their meaning or pronunciation even though the term synform is a form-related issue. Tulip did not provide students with explanations based on the morphology of synforms, for example, a feature inducing more difficulty than its semantic features. There are, although rare, instances in the classroom transcripts where both orthographical and semantic aspects were equally involved in students' confusion. These instructional segments were not included in the present paper on the grounds that word pairs (e.g. deviate/divert) do not meet the criteria set out by Laufer (1991).

Tulip recognised the students' misconception that there is always a relationship between lexical items in terms of formal and semantic features. Her personal theories of teaching with respect to the way she approach synforms seem to be shaped by factors related to students and the nature of lexical items. Student-related factors refer to their specific lexical queries and their deficient responses (i.e. responses that cannot be made after being elicited by the teacher). Those deficient responses are not necessarily lexical errors strictest sense of the word but they derive from poor retrieval of L2 word forms. These factors emerged in her reflection on Episode 1:

"I think if it came from the students themselves if the students come up with such associations we cannot ignore that. But I don't think we should be saying these words sound similar let's have a look at them. They should be taught if they are initiated by the students themselves."

\begin{tabular}{|l|l|}
\hline EPISODE 1: [Students are expected to identify T/F Statements after listening to a recorded lecture about the characteristics of a good team] \\
Competent/competitive [Category 2: synforms with the same root, but different suffixes] \\
T: All of them [team members] should be competent... & 1 \\
What was the meaning of competent by the way? & 2 \\
If you are competent ... (5 sec wait time) what does that mean? & 3 \\
S1: rekabetci (meaning competitive) & 4 \\
T: ahh no that is competitive. A competent person is somebody & 5 \\
(5 second wait time). & 6 \\
I didn't expect it would be the word you don't know. Did not we & 7 \\
have this word before? & 9 \\
S2: huh...telafi (meaning compensation) & 10 \\
T: (laughing) that is compensation. A competent person is a & 11 \\
person who is good at what they are doing so if he is a manager & 12 \\
a competent manager is a good manager a good-skilled manager. & 13 \\
Or whatever you are doing is competent in tennis for example that & 14 \\
means you are a good tennis player....This means everybody in the team & 15 \\
needs to be good at what they are doing. OK....so it was false. & 16 \\
T: Question 4 & 17 \\
S3: true & 18 \\
T: good &
\end{tabular}

It should be noted, though, that Tulip did not always act upon her usual personal theory of teaching. Episode 3 is a case in point. In this particular episode, she focused on the difference between affect and effect which runs counter to her theory 'don't teach synforms together'. When asked why Tulip adopted a somewhat different approach she recalled her prior teaching experience:

'I wouldn't normally teach them together these confusing words ... I remember I once taught students erm... it wasn't something that they had come up with it was not really part of the context. The two words sounded similar they 
looked similar then I said by the way this word sound similar and looked similar....but it has a completely different meaning and ... throughout the course they confused the two. They confused and they made me think...but I believe that it's sometimes necessary to show the students the difference between them. This might hopefully enable them not to make the same mistake twice in the future....yeah..."

In the above account, Tulip made an explicit reference to her previous teaching experience which affects her behaviour she displayed in Episode 2. The lexical items such as affect/effect are notoriously and frequently confusing for many students due to their similar sound and script pattern. Perhaps that is why she requested clarification ('what did you say?' line 6) and checked students' understanding ('Is it clear Cagla?' line 15).

EPISODE 2: Post-Listening: Categorising words as negative/positive/neutral.

Affect/effect: [Category 6: Includes synforms identical in all phonemes except for one vowel/diphthong in the same position]

T: Look at the words in the box to check if you remember them.

There might be some words which you should first check their meaning first.

Affective?

S: neutral

T: what is the meaning of affective here? Often it's actually confused with

another word. [Writing on the board: affective / effective]

S: emotional

T: Alper what did you say?

S: emotional

T: we learnt this before, didn't we? affective... erm factors, about your feelings

Effective means how well you do something, but affective is emotional ... affective

is not very clear, Cagla [asking a student to check if the student has problem with it]

S: verimli?

T: is it verimli? (meaning efficient) [Aside] is it efficient I wonder. They are close

aren't they? Effective and efficient are close they seem to be about verimli

(meaning efficient), what is effective? If you plan is an effective plan for example

it is a plan that work well so is...'etkili' (meaning effective) is good or 'ise yarar'

(meaning useful). Is it clear Cagla?

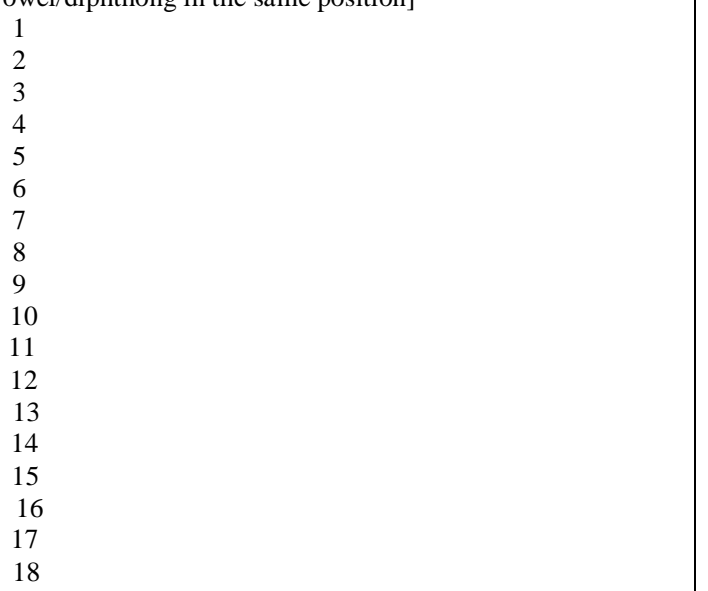

Tulip`s reference to the frequency (how many times a synform causes problem for students) and the recency (when the teacher presented either of synforms) is evident in her following account implies that she takes into consideration time-related issues:

"I think I would draw their attention to similar words if they constantly cause difficulty to learners...also I would teach these words if I have recently taught them in previous units"

In line with the principle of 'integrate new words with old', or connecting previous and new knowledge, Tulip's reference to temporal aspects of classroom teaching also shows the extent to which she monitors Ss' and her own input throughout the course. Reflecting on Episode 3, she said, 'I encourage them that they shouldn't be translating everything from English to Turkish. Not direct explicit translation because it makes things much more complicated'.

EPIDOSE 3: [Post-Reading: Teacher read out a sentence on the worksheet for the students to fill in the blank].

Contradictory- controversial [Category 4: synforms with the same root, but different suffixes]

S: controversial

T: not controversial but you are very close

S: contrast? 3

$\mathrm{T}$ : contrasting, OK this is contrasting you can say good [praise] it is contradictory ok 4

S2: celiski

T: yeah, newspapers one thing the other side says something completely different.

The information contrast each other that's good.

S1: celiski [repeating the word silently]

During Episode 3, Tulip did not provide the answer straight away, rather she tended to withhold the word necessary for sentence completion saying 'but you are very close' (line 2). Again her justification is based on the factors related to students themselves:

The target word was contradictory. Maybe because it is confusing hmmm... [sighs] I don't know I don't have a real rational for that. It is not like I introduced words out of the blue. They are the words that come from the students. So they wanted to fill in the blank with the word contrast. Either they are not sure about the meaning of the word or that it has the meaning of contrast. As they share the first 5 letters in common it makes sense to focus on the meaning of the words.

There are some occasions when Tulip withheld correct answers and made use of elicitation and clarification requests using expression like 'say that again' (see Episode 4: line 9). She again referred to students' characteristics in her account as follows:

'It is my gut feeling here that helped me more than anything and the student's facial expressions and gestures as I can remember her trying to say what she was saying now. Gulcin [student] can take risks. When she is stuck, either me or her friends help her out but somehow she can express herself. To me, this is something good and positive'. 
Episode 4: [SPEAKING: Students are sharing their ethical views about various topics listed in the coursebook]

Criteria/creation [Category 4: synforms with the same root, but different suffixes]

T: [Reading out another dilemma]: As an engineer, to ignore a dangerous situation you have accidentally created.

You built something maybe without realizing it is dangerous, is it OK to turn a blind eye to it not see it ignore it

S: no they are responsible for the human life

T: ok so you wouldn't do that you think the engineers have to tell the people about the possible dangers trying to fix it maybe...

S: They are not doing right but the creations ... erm ... they have made have to be safe I think

T: hae

S: unless there are not creations

T: say that again

S: unless they are not creations because everybody do and create something there are some ... erm [murmuring some Turkish words, thinking of a word to complete her sentence]

T: himmm...

S: it has to be in some shape to be a creation

T: it has to fulfill some sort of criteria to be creations, basically you are saying if there is a dangerous situation they should take on the responsibility is that the general feeling?

Ss: yes, exactly.

Episode 5 occurred in a reading comprehension activity during which students were expected to answer questions about a news story taken from CNN.com. Tulip herself initiated the word 'pertinent' asking 'is this a word you know? Line1). Regarding this episode she commented:

It was the beginning of the sentence [erm...correction] word. They use...they use the sound to help them and guess the meaning of the word. The sound and the appearance of the word... Not the sound erm...sorry the letters themselves...how the word looks like They guessed the word because of -per I imagine. They looked at the word pertinent and it just sounds like permanent.

EPIDOSE 5: [READING: Students are expected to answer comprehension questions]

Pertinent - Permanent [Category 4: synforms with the same root, but different suffixes]

T: Here it means pertinent ... Is this a word you know?

S: devamli (permanent in Turkish)

T: not devamli, that's permanent ha ha. Per-ti-nent

S: (thinking...trying to remember, looking it up)

S: alakali (pertinent in Turkish)

$\mathrm{T}$ : alakali, ilgili. Think of it as essential, very important, crucial

1
2
3
4
5
6

\section{DISCUSSION}

In the light of classroom observations and their personal theories underlying their classroom practices, the study examined how an EAP teacher approach the particular lexis-related phenomenon called 'synforms'. Synform pairs appeared in a wide range of activities including vocabulary revision: Episode 3, reading: Episode 5, listening comprehension: Episode 1 and 4, and discussion: Episode 2, which are carried out at different stages of lessons. There was no writing activity during which the teacher dealt with synforms, though. This is not surprising because teachers give feedback to students' compositions outside the classroom hours, namely during their appointed tutorial hours. It also turned out in terms of categories of synforms, Episodes predominantly belong to type 4, that is synforms with the same root, but different suffixes, which supports Tulip's assumption that students tend to 'use the sound to help them and guess the meaning of the word'.

The teacher, Tulip, acknowledged the confusion caused by synforms during formal instruction. She accordingly tended to give students further explanations from time to time particularly when she dealt with students' deficient responses (i.e. responses that cannot be made after being elicited by the teacher). The way she dealt with synforms is mostly governed by students' emergent reactions in general and misunderstanding of different kinds, emphasising the importance of providing learning opportunities for students during classroom interactions, as advocated by Allwright and Bailey (1991). This also confirms the results of a form-focused instruction study (Zhao and Bitchener, 2007:444) which suggest that teachers were more active than learners in responding to learners' errors because of the large number of reactive form-focus episodes in teacher-learner interactions. Tullip appeared to be responsive to students' synformic confusions when they were involved in different types of activities ranging from reading comprehension questions to listening T-F statements to consolidating vocabulary. Reactivity on the part of the teacher looked as if it is quite biased towards one particular (individual) member of the synform pair which varies depending on its relevance to the content of the activity dealt with. The fact that some of the synform errors could be induced by the tasks, to some extent, reinforces Henry and Metussin's (1999) findings suggesting the crucial role of the nature of tasks in students' errors. In the case of Tulip, the connection between the message of the activity and the lexical items is emphasised. Her reactive treatment of a synform seems to be influenced by factors (i.e. personality, attitude and context) proposed by Andrews (2001). For example, Tulip's alertness (especially in the case of identifying learners' wrong answers, not necessarily erroneous linguistic or lexical errors), her willingness to deal with lexical forms/meanings and time constraint account for the approach Tulip adopts towards dealing with synforms. In his framework, however, Andrews has made no mention of the role of teachers' L1 knowledge. This component is particularly important for Turkish language which 
has a sound-script congruence and even vowel harmony. Vowel harmony is defined by Crystal (1992) as 'a type of assimilation which takes place when vowels come to share certain features with contrastive vowels elsewhere in a word or phrase'. Through such L1 knowledge teachers need to be alert to students' input so that they can detect the sources of errors committed by learners during classroom interaction.

Tulip attempts to limit the potential sources of learner confusion in the input by urging her students to avoid translating whatever they hear and read. This shows the extent to which she is aware of the inhibitory role of L1 problem coupled by some students' unsolicited use of L1. An alternative explanation could be that the teacher's reactive, albeit partial, attitude towards synforms depend heavily on constraints related to lesson planning, as can be inferred from the teacher' illustrative account in Findings section where she referred to her 'rough' lesson planning due to her tight schedule. One way of addressing this problem, according to Henry and Metussin (1999), is that sensitise teachers to become aware of the likely problems synforms may bring about by keeping them apart in the syllabus. LauferDvorkin (1991: 194) suggests that 'if the synform of a new word was learnt at an early stage, it is very desirable that the class should be reminded of it and the contrast between the synforms should be pointed out' (emphasis mine). This highlights the extent to which teachers should ideally bring synforms to students' attention. As the word 'remind' implies, only limited focus on those items that may have been previously taught was considered to suffice, rather than extensive elaboration on two or more members of synforms. Indeed, synforms do not lend themselves to be readily identified especially when they occur during teacher- student interaction which is interactive and dynamic. Such unpredictability might be coupled with the students' L1 utterances. It is sometimes inevitable that students' guesses or approximations, for example, might involve semantic or phonological (or both) association between L2 lexical items. Combined effect of intrinsic deceptiveness of synforms and the difficulty to determine students' intention might account for the way in which the teacher treated synforms.

The teacher's avoidance of treating numerous words together (by comparing them) can be justified on the grounds that this may lead to what I call the 'word-within-word' (WWW) phenomenon. The phenomenon refers to an occasion in which several other words are explained by the teacher although they are not directly relevant to the target lexical item they intend to teach in the first instance. This corresponds to the issue of maintaining the flow of communicative activity about which teachers have most of their inconsistencies between their beliefs and practices (Basturkmen, et.al. 2004; Ellis et.al.2001). The present study also corroborates Osam and Balbay's (2004) research which suggests that both experienced and inexperienced teachers makes instant decisions to such an extent that they depart from their lesson plans. It turned out that most of the WWW instances occur especially when the teacher elicited words from her students. Students' utterances following her elicitations seemed to change the direction of the lesson, which is an indicative of her responsiveness. This finding supports Hatch and Brown's (1995) conclusion that elaboration on form or meaning might disrupt the flow of classroom. Such obtrusive semantic elaboration is something which is considered to exert negatively on lexical input processing (Barcroft, 2004). After all, the forms initiated by the teachers themselves do not necessarily constitute potential rather than actual gaps in the students' knowledge (Ellis, et.al. 2002:431).

\section{IMPLICATIONS}

In order for teachers to direct students' attention on formal properties of lexical items they need to be aware of both interlexical and intralexical factors that play crucial role in vocabulary learning and teaching. Lexical items may have incomplete representations and thus various associative traces in the students' mind shaped by their personal life experiences and language learning experience. Without raising students' awareness about synform pairs (either individually or in tandem) they may go unnoticed. Therefore, in addition to oral/verbal input, teachers should also encourage repetition and rehearsal supported by written/visual input where appropriate to compensate for such partial representation (Hummel and French, 2010:383). During the initial stages of learning new words for effective vocabulary instruction it is recommended that teachers limit semantic elaboration (a situation in which one focuses extensively on meaning-related properties of a word due to its inhibitory or negative influence on the ability to encode the formal properties of new L2 words) (Barcroft, 2004:205). Activities such as generating a series of words related in meaning to a target word and answering questions may decrease learners' ability to learn new word forms on the grounds that memory for L2 words depended more on memory of word form (p.206).

\section{CONCLUSION}

The study suggested the participant teacher seemed to base her instructional decisions on a number of factors such as student, words, and time. These conditions acknowledge that teachers in different contexts employ different strategies and resources available to them. In fact, lexis teaching is 'more than just introducing new words, it also includes nurturing partially known vocabulary along to the point where learners can use it at will' (Schmitt, 2000: 157). The issue is not whether to teach synforms or not, but the time when the way how they should be responded by the teacher. It is therefore necessary for language teachers to be responsive to student-generated queries about lexical items, particularly synformy. Future research could investigate both teachers' and students' attitude towards the same lexical phenomenon based on the quantitative aspects such as frequency of focus on lexis episodes and percentage of feedback 
moves. The present study might serve as a stimulus for debate as to whether the phenomenon of synformy should receive a special teaching type and, if yes, what kind of pedagogical options are conducive to its treatment.

\section{ACKNOWLEDGEMENT}

I extend my thanks to Prof. Nina Spada, Dr. Simon Gieve and Dr. Simon Borg for their inspiration and encouragement.

\section{REFERENCES}

[1] ANDREWS, S. (2001). The language awareness of the L2 teacher: Its impact upon pedagogical practice. Language Awareness, 10(2-3), pp. 75-90.

[2] ANDREWS, S. and MCNEILL, A. (2005). Knowledge about Language and the 'Good Language Teacher. In: N. BARTELS, ed, Applied Linguistics and Language Teacher Education. USA: Springer, pp. 159- 178.

[3] BARCROFT, J. (2004). Second language vocabulary acquisition: A lexical input processing approach. Foreign Language Annals, 37(2), pp. 200-208.

[4] BASTURKMEN, H., LOEWEN, S. and ELLIS, R. (2004). Teachers' Stated Beliefs about Incidental Focus on Form and their Classroom Practices. Applied Linguistics, 25(2), pp. 243-272.

[5] BEGLAR, D. and HUNT, A. (2005). Six principles for teaching foreign language vocabulary: A commentary on Laufer, Meara, and Nation's "Ten Best Ideas". The Language Teacher, 29(7), pp. 7-10.

[6] BENSOUSSAN, M. and LAUFER, B. (1984). Lexical Guessing in Context in EFL Reading Comprehension. Journal of Research in Reading, 7(1), pp. 15-32.

[7] BORG, S. (2009b). Language teacher cognition. In: A. BURNS and J.C. RICHARDS, eds, Cambridge guide to second language teacher education. Cambridge: Cambridge University Press, pp. 163-171.

[8] BORG, S. (2009) Introducing language teacher cognition. Available: http://www.education.leeds.ac.uk/people/staff.php?staff=29 11/12/2009.

[9] BORG, S. (2003). Teacher cognition in language teaching: A review of research of what language teachers think, know, believe, and do. Language Teaching, 36(2), pp. 81-109.

[10] BREEN, M.P., HIRD, B., MILTON, M., OLIVER, R. and THWAITE, A. (2001). Making Sense of Language Teaching: Teachers' Principles and Classroom Practices. Applied Linguistics, 22(4), 470-501.

[11] COLLIE GRADEN, E. (1996). How language teachers' beliefs about reading are mediated by their beliefs about students. Foreign Language Annals, 29(3), pp. 387-395.

[12] COXHEAD, A. (2000). A New Academic Word List. TESOL Quarterly, 34(2), pp. 213-238.

[13] CRYSTAL, D. (1992). An encyclopedic dictionary of language and languages. Cambridge: Blackwell.

[14] DOBINSON, T. (2001). Do learners learn from classroom interaction and does the teacher have a role to play? Language Teaching Research, 5(3), pp. 189-211.

[15] ELLIS, R., BASTURKMEN, H. and LOEEWEN, S. (2001). Pre-emptive focus on form in the ESL classroom. TESOL Quarterly, 35, pp. 407-432.

[16] ELLIS, R., BASTURKMEN, H. and LOEWEN, S. (2002). Doing focus-on-form. System, 30(4), pp. 419-432.

[17] FILE, K. A. AND ADAMS, R. (2010). Should Vocabulary Instruction Be Integrated or Isolated? TESOL Quarterly, 44(2), pp. 222-249.

[18] FOLSE, K. (2004). Vocabulary Myths: Applying Second Language Research to Classroom Teaching. Ann Arbor: Michigan University Press.

[19] HANNA, P.R., HODGES, R.E. and HANNA, J.S. (1971). Spelling: Structure and strategies. Boston: Houghton Mifflin.

[20] HATCH, E. and BROWN C. (1995). Vocabulary, Semantics, and Language Education. Cambridge University Press: Cambridge.

[21] HENRY, A. and METUSSIN, D.R.P.H. (1999). An Investigation into the Levels of Difficulty of Certain Semantic Word Classes in a Bilingual Setting. International Journal of Bilingual Education and Bilingualism, 2(1), pp. 13-29.

[22] HUMMEL, K.M. and FRENCH, L.M. (2010). Phonological Memory and Implications for the Second Language Classroom. The Canadian Modern Language Review, 66(3), pp. 371-391.

[23] LAUFER, B. (1988). The concept of 'synforms' (similar lexical forms ) in L2 vocabulary acquisition. Language and Education, 2, pp. 113-132.

[24] LAUFER, B. (1997). What's in a word that makes it hard or easy? Intralexical factors affecting the difficulty of vocabulary acquisition. In: M. MCCARTHY and N. SCHMITT, eds, Vocabulary Description, Acquisition and Pedagogy. Cambridge: Cambridge University Press, pp. 140-155.

[25] LAUFER, B. P. MEARA AND P. NATION (2005). Ten best ideas for teaching vocabulary. The Language Teacher, 29(7), pp. 3-6.

[26] LAUFER-DVORKIN, B. (1991). Similar lexical forms in interlanguage. Gunter Narr: Verlag Tubingen.

[27] McNEILL, A. (2005). Nonnative speaker teachers and awareness of lexical difficulty in pedagogical texts. In: Non-Native Language Teachers: Perceptions, Challenges and Contributions to the Profession. Springer, New York. 107-128.

[28] MOJE, E.B. (1996). I teach students, not subjects: Teacher student relationships as contexts for secondary literacy. Research Quarterly, 31(2), pp. 172-195.

[29] NATION, I.S.P. (2001). Learning Vocabulary in Another Language. Cambridge: Cambridge University Press.

[30] NATION, I.S.P. (1990). Teaching and Learning Vocabulary New York. New York: Newbury House.

[31] OSAM, U.V. and BALBAY, S. (2004). Investigating the decision-making skills of cooperating teachers and student teachers of English in a Turkish context. Teaching and Teacher Education, 20(7), pp. 745-758.

[32] PRABHU, N.S. (1990). There is no best method - why? TESOL Quarterly, 24(2), pp. 161-176. 
[33] SCHMITT, N. (2008). Instructed second language vocabulary learning. Language Teaching Research, 12, pp. 329-363.

[34] SCHMITT, N. (2000). Vocabulary in Language Teaching. Cambridge: Cambridge University Press.

[35] SEEDHOUSE, P. (1997). Combining Form and Meaning. ELT Journal, 51(4), pp. 336-344.

[36] SLIMANI, A. (1991). Evaluation of classroom interaction. In: J.C. ALDERSON and A. BERETTON, eds, Evaluating language education. Cambridge: Cambridge University Press.

[37] SMITH, C. and TAJINO, A. (2003). Teachers' Perceptions of Learner Difficulty in Vocabulary Learning. Available: http://www.developingteachers.com/articles_tchtraining/tchvocabpf_craigakira.htm [January/5, 2010].

[38] SÖKMEN, A. (1997). Current trends in teaching second language vocabulary. In: N. SCHMITT AND M. MCCARTHY, ed, Vocabulary: Description, Acquisition and Pedagogy. Cambridge: Cambridge University Press.

[39] SPADA, N. AND LIGHTBOWN, P.M. (2008). Form-focused instruction: Isolated or Integrated? TESOL Quarterly, (42), pp. 181-207.

[40] STURTEVANT, E.G. and LINEK, W.M. (2003). The instructional beliefs and decisions of middle and secondary teachers who successfully blend literacy and content. Reading Research And Instruction, 43(1), pp. 74-90.

[41] ZHAO, S.Y. and BITCHENER, J. (2007). Incidental focus on form in teacher-learner and learner-learner interactions. System, 35(431), pp. 447.

Sukru Nural was born in Istanbul, Turkey in 1983. He received his PhD degree in applied linguistics from University of Leicester, United Kingdom in 2014. He is currently an EAP tutor in the School of Foreign Languages, Galatasaray University, Istanbul. His research interests include language teacher cognition and lexis. Dr. Nural is a member of the British Association Applied Linguists. 